\title{
Fetal Behavior at 30 to 32 Weeks of Gestation
}

\author{
(i. H. A. VISSER. (;. POHIMANVWHESIES. T. M. N. (CHHEN. ANI) D. J. BIKKEDAM

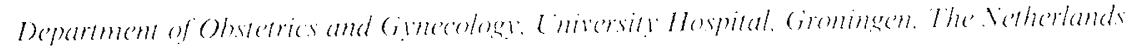

\begin{abstract}
Coordinated behavior states with concomitant variation in cyclic patterns of heart rate and of eye and gross body movements are present in the near term fetus. As in the newborn infant, there is conflicting evidence concerning their relationship at earlier gestational ages. In the present study 120 -min recordings were made of fetal heart rate, eve, and gross body movements in 11 healthy nulliparous women who were 30 to $32 \mathrm{wk}$ pregnant. From the presented data it is concluded that at this gestational age heart rate variation and eye and gross body movements are not independent variables and that coordination among the cyclic patterns of these variables starts well before 36 wk. (Pediatr Res 22: 655-658, 1987)
\end{abstract}

\section{Abbreviations}

REM, rapid eye movement

In the full-term newborn inlant behavioral states are characterized by relatively stable periods of time with particular combinations of well-defined behavioral characteristics. At transitions between states the different state variables change simultaneously. On the basis of both observational and polygraphic studies in the newborn infant. behavioral or sleep states can be recognized from 35 to 37 wk onward (1-3). Before that time cycles of regular/irregular breathing. episodes of rapid/nonrapid eve movements and motility/quieseence are independent of each other according to a study of Prechtl ot al. (1).

After 36 wk gestation in the human fetus coordinated behavioural states are present with concomitant variation in cyclic patterns of heart rate and of eye and body movements (4). Before this age cycles of each of these variables also are present (4) and between 28 and 36 wk significant relations of heart rate variation with gross body movement pattern $(5,6)$ and of body movemen. with eye movement incidence (7) have been reported. According to Nijhuis (' al. (4). however, the relatively short duration of combinations of particular states and the lack of simultaneity of combinations of particularsates and the conclusion that before 36 wk the periods of state coincidence occur by chance and do not represent organized behavioral states. In the latter study the same assessment technique was used as by Prechtl of al. (1) in newborn infants. namely a 3 -min moving window by which body movements and eve movements are classified as being either absent or present.

Recently several authors have shown that in the preterm newborn infant differentiation between active and quiet sleep is possible using EI: ( $;$ and REM criteria (8. 9). Moreover, at least from 31 wk postmenstrual age onward, movements predominate in active as compared to quiet sleep (10). In order to determine

Received December 15.1986: accepted July 29, 1987

(iorrespondence and repeint requests (i. H. A. Visser. Deparment of Obstetrics and (ivnakcology, Iniversity Hospital, 59 Oostersingel. $97131 \%$ C (ironingen. The Neverlands.

Supported by the Dutch Beatrix Foundation (irant 801743 . whether there is a coordination among the eyclic pattems of heart rate. gross body movements. and exe movements in the 30) to 32-wk-old fetus we studied these variables in 11 fetuses of this gestational age. This age was chosen because it is likely to be the earliest at which associations might be found. This holds for the preterm newborn infant $(10.11)$ as well as for the tetus. In the fetus relations between heart rate and gross body mowement patterns and between body movements and eve movement incidence were demonstrated previously only from 28 and 30 wh onward. respectively (6.7).

\section{PATIENTS AND MFIHIOISS}

Fleven healthy nulliparous women with normal pregnancies of 30 to 32 wk were invited to participate. The duration of pregnancy was calculated from the lst day of the last menstrual period. In all 11 women this duration had been validated during the first trimester by ultrasound measurements of (rown-rump length and biparietal diameter. The subsequent course of pregnancy and delivers were uneventful. All infants were born after $37 \mathrm{wk}$ of gestation, were appropriate for dates (birth weight 3100 10 $4190 \mathrm{~g}$ ). and did well at and after birth. I)uring pregnancy none of the women were on medication and they did not smoke.

The studies took place between 1600 and $1900 \mathrm{~h}$ and hatd al duration of $120 \mathrm{~min}$. Records were made with the women lying in a semirecumbent position. Fetal heart rate was measured using an ultrasound transducer and was recorded on a cardiotocograph strip chart (Hewlett Packard 8()40 A). Fye and gross body movements were observed using two linear array real-time scanners (Searle 2300 and Aloka 256). The seanners were held so that a sagittal section of the fetal trunk and an oblique-sagittal transsection of the fetal face. including an eve (12), were visible retal eve and gross body movements were recorded digitally. with the use of an event marker and. with fetal heart rate encoded on an analog 7 tape recorder and on an erent recorder. $A$ compressed 120)-min record is shown in Figure 1.

Fetal heart rate records were assessed visually by an investigator not involved in the study and were subdivided as patterns a and $B$, using the criteria defined by Vijhuis et al. (4). In pattern $\triangle$ heart rate is stable. with a small oscillation bandwidth: isolated accelerations may occur. In pattern $B$ heart rate has a wider oscillation bandwidth and frequent accelerations occur. Patterns $C$ and $D$ (with a wide oscillation bandwidth and an absence of accelerations or the presence of prolonged acederations. respeclively) were categorized as pattern $B$ in the present study. Iise movements were quantified by cakculating their number per minute and gross body movements by calculating the percentage of time they occupied per minute.

Original data on 1 -min cee and gross hody movement incidence were used for studving their relationship with the two heart rate patterns. As for the relation between we and body movement patterns, data were reduced by calculating the ir incidence in 4min epochs. As prolonged body movements often prevent adequate simultancous observation of eve mowements. these data were smoothed by using a low pass tilter $\left(t_{1}=0.5 \mathrm{t}\right.$ $\left.+0.5 t_{1}, 1\right)$. This filter transmits all of the fowest frequency 


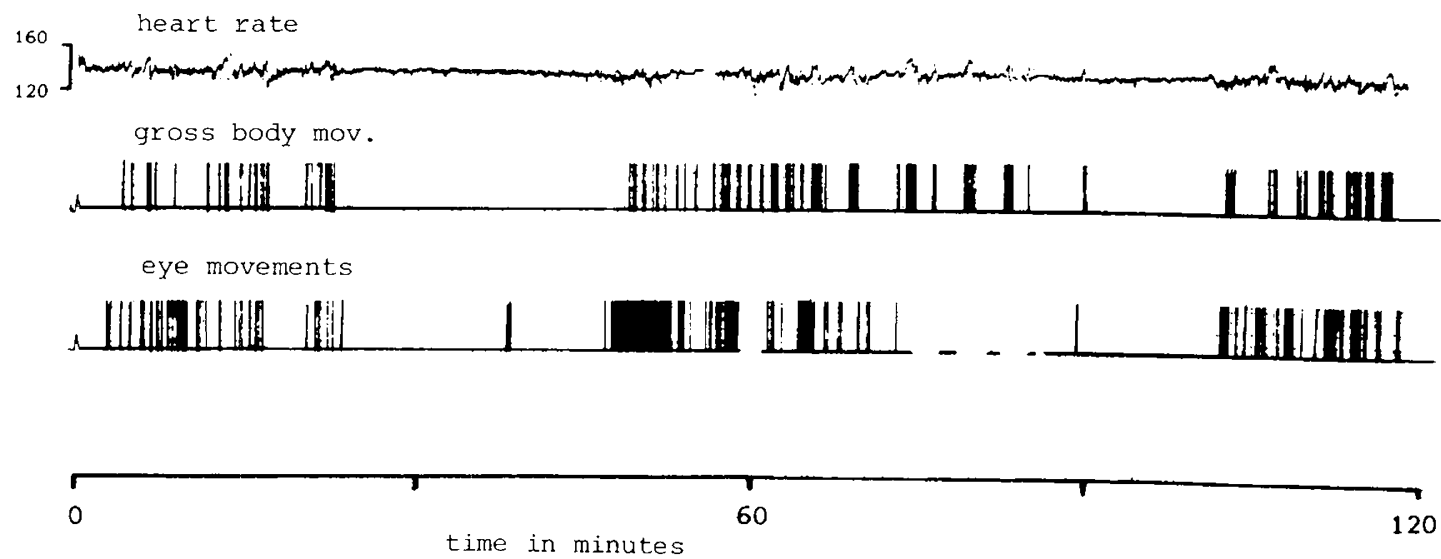

Fig. 1. Example of a record of fetal heart rate, gross body movements, and eye movements taken at 31 wk gestation.

components in the time series $t_{n}$; it transmits only half of the power of a component with a frequency of 1 cycle per 8 min and nothing at frequencies of 1 cycle per $4 \mathrm{~min}$ and higher (transfer function $G^{2}(f)=1 / 2(1+\cos 2 \cap f)$. With this technique artifacts induced by not observing eye movements are prevented as much as possible, while the cyclic patterns of eye and gross body movements and their relationship can still be analyzed.

The relationship between the 4-min eye and body movement incidence was studied per patient by calculating the correlation coefficient. Using the Fisher $Z$ transformation test the correlation coefficient was calculated for the total group. The paired $t$ test was used to compare the incidence of eye and gross body movements during episodes with fetal heart rate patterns $\mathrm{A}$ and $\mathrm{B}$.

\section{RESULTS}

All fetal heart rate records showed episodes of pattern A and B. Pattern A was, on average, present $23 \%$ of the time (range 8 to $41 \%$ ) and pattern B $61 \%$ (range 38 to $74 \%$ ); $16 \%$ of the time it was not possible to classify the heart rate pattern, usually because of the poor quality of the recording. The median duration of a complete episode of heart rate pattern $\mathrm{A}$ was 18 min (range 7 to $35 \mathrm{~min}$ ) and that of a complete cycle of pattern $A$ and B $50 \mathrm{~min}$ (range 40 to $75 \mathrm{~min} ; n=7$ ). Including cycles that were not completed within $120 \mathrm{~min}$, a median cycle length of 66 min was found.

In all fetuses the incidence of eye and gross body movements was lower during heart rate pattern A than during pattern B (Fig. 2 ; paired $t$ test, $p<0.005$ ). The median values were 0.4 and 3.8 per min, respectively, for eye movements and 2.1 and $12 \%$ of time per min for gross body movements.

Based on these data 4-min epochs were considered to have a low eye or gross body movements incidence if during such an epoch four or fewer eye movements were observed or if body movements occupied less than $4 \%$ of the time. The relationship between the heart rate patterns $\mathrm{A}$ and $\mathrm{B}$ and concomitant low or high incidence of eye and/or body movements is shown in Table 1. A total of $57 \%$ of the time both eye and gross body movements were of low incidence during pattern $A$; during pattern B both movements were of high incidence $74 \%$ of the observation time.

Assessed visually, in four cases there was a striking correlation between eye and gross body movement patterns (Fig. 3); on six occasions the patterns corresponded reasonably well (Figure 4), while on one occasion no relation could be seen (Fig. 5). Statistical analysis showed a significant correlation between 4-min epoch incidence of both types of movements in seven fetuses $(r$ $=0.41$ to 0.79$)$; in the other four fetuses no significant correlation was found $(r=-0.16$ to 0.29$)$. Using the Fisher $Z$ transformation test, a significant correlation between the two variables was demonstrated in the total group $(r=0.44 ; ;<0.0005)$.

One of the main characteristics of behavioral states is that at
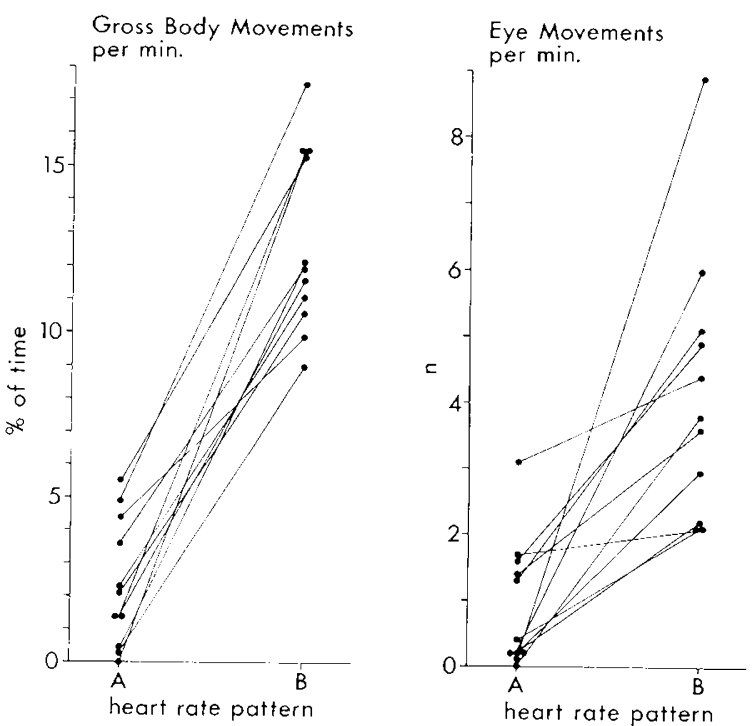

Fig. 2. Incidence of fetal gross body movements and of eye movements during heart rate pattern $\mathrm{A}$ and $\mathrm{B}$. Each dot represents an individual.

transitions between states the different state variables change simultaneously. This aspect was investigated by studying changes in eye and gross body movement incidence within 4 and 6 min of a change in heart rate pattern. Episodes were considered to have a low eye or gross body movement incidence if during two or more consecutive 4-min epochs the incidence of eye movements was equal to or less than four per 4 min or body movements occupied less than $4 \%$ of the time. Changes in pattern of the variables were considered to be in agreement with each other if a change from heart rate pattern $A$ to $B$ was associated with a change of both eye and body movements from low to high incidence, or if a change from pattern $B$ to $A$ was associated with a reduction in incidence of both types of movements.

On 31 occasions a change in heart rate pattern was observed. In no case did both eye and body movements incidence change in the inappropriate direction within $6 \mathrm{~min}$ of this change. In contrast, a change in both patterns corresponding to the change in heart rate pattern was observed on 15 occasions within $4 \mathrm{~min}$ $(48 \%)$ and on 22 occasions within 6 min $(71 \%)$. If the pattern changes of the three variables were totally independent of each other, theoretical percentages of 1 and 3 would have been expected (taking into account the number and direction of the pattern changes). Percentages of 3 and 6 were found when three randomly determined 8 - and 12-min episodes were taken, during which no change in heart rate pattern occurred. The number of 


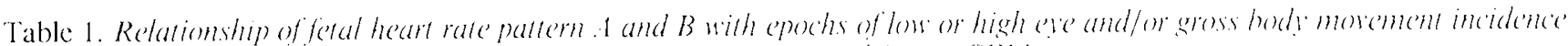
(expressed as percentage of time \pm St:Hi)

\begin{tabular}{|c|c|c|c|c|}
\hline \multirow[b]{2}{*}{$\begin{array}{l}\text { Setal heart } \\
\text { rate pattern }\end{array}$} & \multirow[b]{2}{*}{$\begin{array}{l}\text { Percentage } \\
\text { total recording time }\end{array}$} & \multicolumn{3}{|c|}{$\begin{array}{l}\text { Coincidence with epochs } \\
\text { of high or low eve and/or } \\
\text { general movement incidence }\end{array}$} \\
\hline & & Both low & One low/one high & Both high \\
\hline $\begin{array}{l}\wedge \\
B \\
\text { Undefined }\end{array}$ & $\begin{array}{c}23 \pm 2.5 \\
61 \pm 3.8 \\
16 \pm 4.6\end{array}$ & $\begin{array}{r}57 \pm 8.2 \\
3 \pm 1.4\end{array}$ & $\begin{array}{l}31 \pm 5.2 \\
23 \pm 5 \\
45 \pm 22\end{array}$ & $\begin{array}{l}12 \pm 3 \\
74 \pm 5.3 \\
55 \pm 21\end{array}$ \\
\hline
\end{tabular}
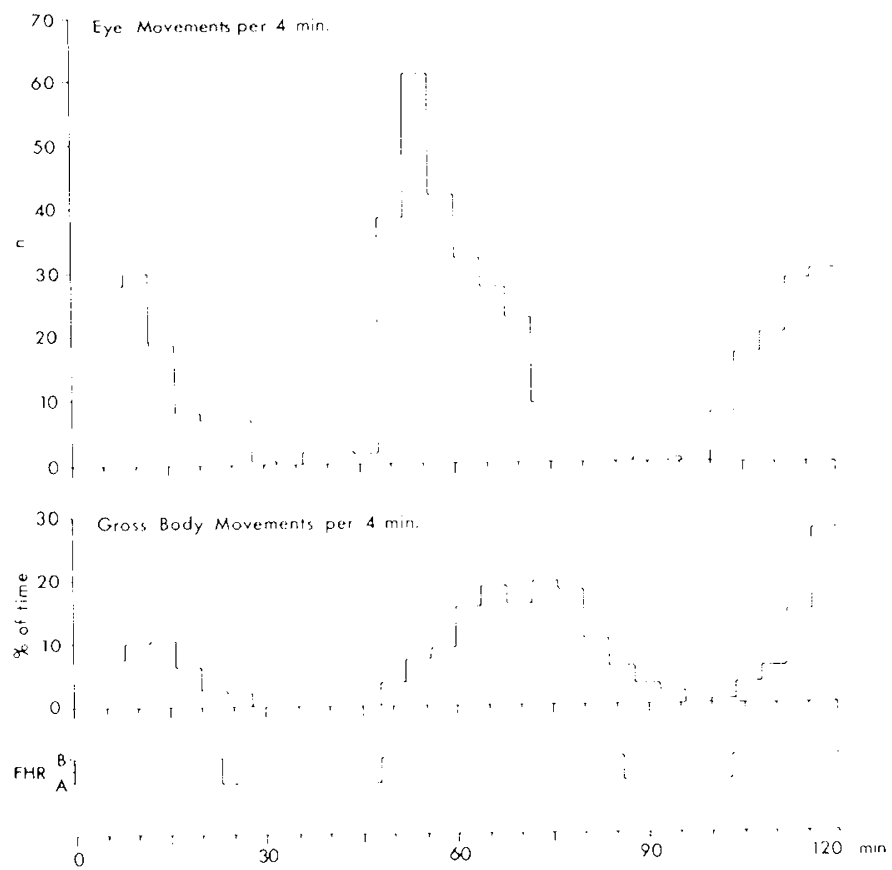

Fig. 3. Ixample of one of the four cases in which there was a good correlation between fetal eye and gross body movements patterns. Between min 76 and 88 a fetal eve could not be visualized. Same record as shown in Figure 1: the correlation coefficient between the incidence of eye and gross body movements was 0.53 .

changes of both eye and gross body movement pattern within 4 to 6 min of changes from heart rate pattern $A$ to $B$ was identical to that of the number of ehanges in the opposite direction when heart rate changed from pattern $B$ to $\wedge$.

Another approach is shown in Figure 6. In episodes in which the heart rate pattern $\wedge$ exceeded 12 min (14 observations in 10 fetuses: data were standardized per fetus). the incidence of eve and gross body movements was calculated during the $6 \mathrm{~min}$ preceding and following a change in heart rate pattern. As seen in Figure 6 as well as from the data presented before, it is clear that at 30 to $32 \mathrm{wk}$ of gestation there is an emergence of coordination between the cyclic patterns of heart rate. eye. and gross body movements.

\section{IDISCUSSION}

Both in the newborn infant and in the fetus clear behavioral states occur at about 36 wh postmenstrual age $(1-4)$. There is. however, conflicting evidence concerning the relationship of the state variables at earlier ages. In the newborn infant DreyfusBrisac (2) noted the appearance of typical active sleep at $35 \mathrm{wk}$ and of typical quiet sleep at $37 \mathrm{wk}$. Before this time. however. active sleep. different from that observed in the full-term newborn, can be recognized (13), whereas quiet sleep, "the last to attain its typical organization". may be recognized as early as 31 wk, but with atypical components (11).

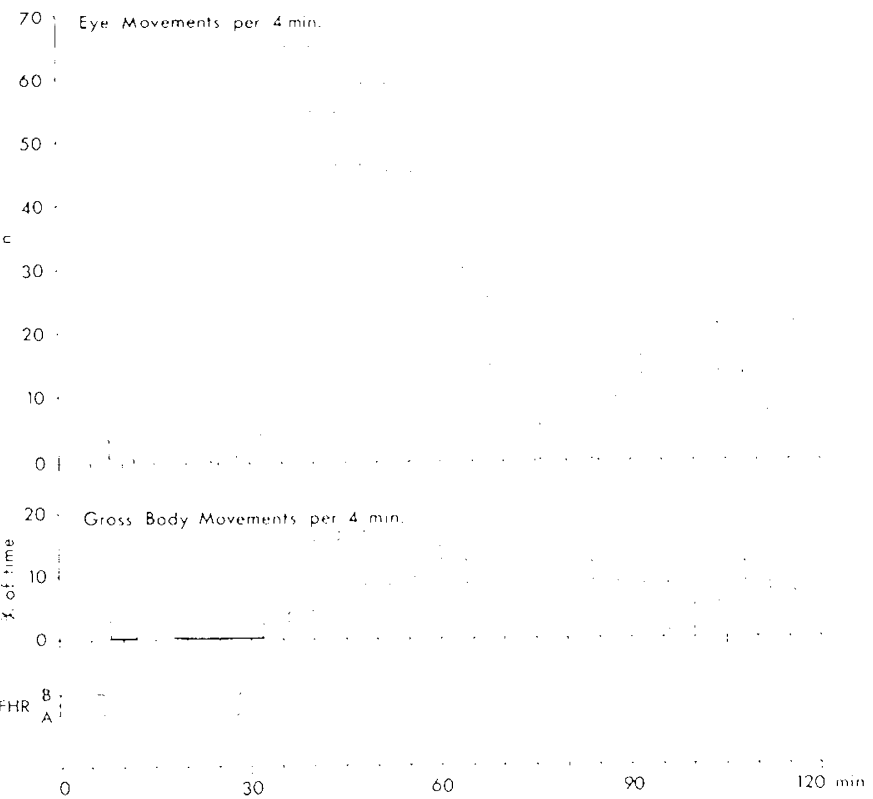

Fig. 4. One of the six cases in which the fetal eye and gross body morements patterns corresponded reasonably well. In this case this was especially true for the first part of the recording. Corrclation coeflicient between the incidence of ere and gross body morements was 0.41

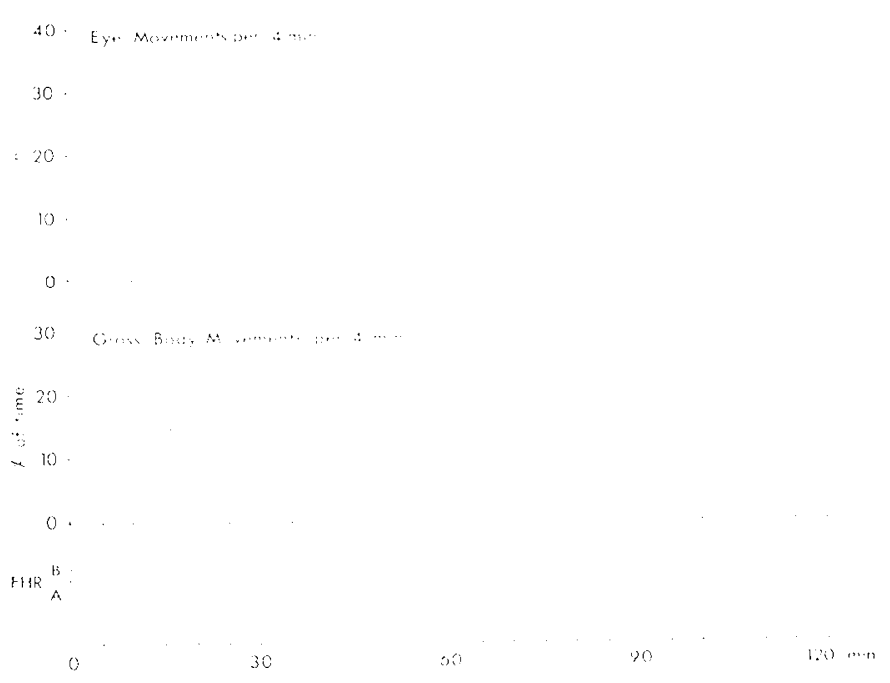

Fïg. 5. Recording in which no relation between fetal eye and gross body movement pattern was present (comelation coeflicient -0.16.). Between min 44 and 6() a fetal cye could not be visualised.

Recently it was shown that in the preterm newborn infant differentiation between active and quiet slecp is possible using FE: 3 and REM criteria (8.9), and it appears that at least from 31 wh postmenstrual age onward movements predominate in active sleep as compared to quiet sleep (10). Thus in the preterm 

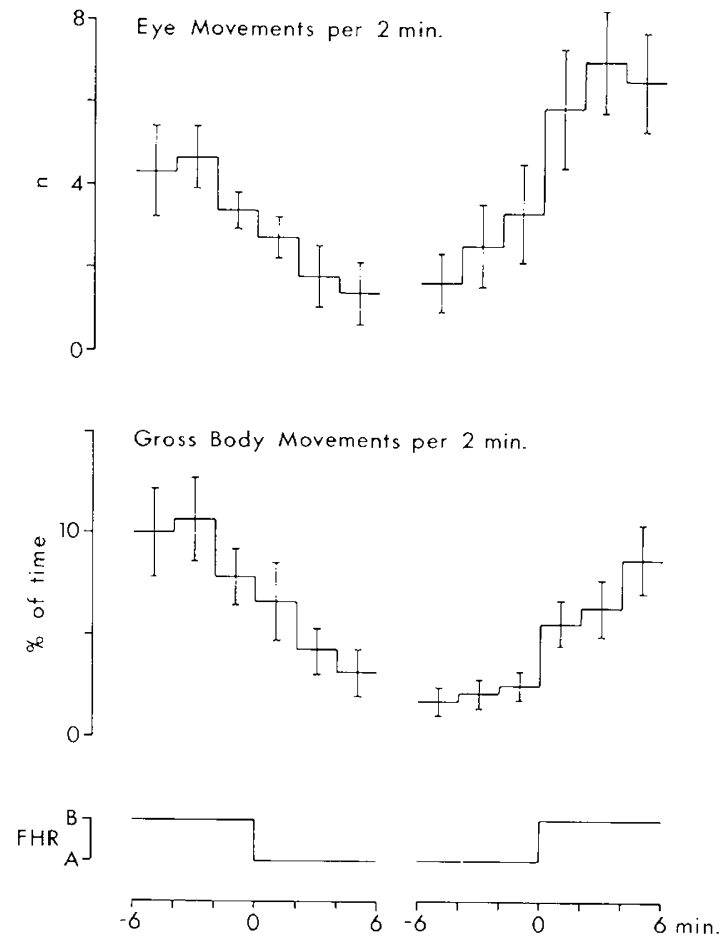

Fig. 6. Incidence of fetal eye and gross body movements (mean and SEM) during the 6 min preceding and following a change in fetal heart rate pattern. Only episodes with heart rate pattern A that exceeded 12 min were studied. Data were standardized per fetus.

infant the relationship between different state variables is not coincidental. In contrast, it shows "the existence of differences in control of physiological variables according to sleep states as early as $31 \mathrm{wk}$ " (10). Discrepancies with the study of Prechtl et al. (1) may be due to the fact that in the preterm infant during quiet sleep, movements are still rather common $(13,14)$. This might explain why, with a technique that does not quantify movements but classifies them as being either absent or present, coordination of state variables cannot be demonstrated before 36 wk. The same holds for the data before birth, as Nijhuis et al. (4) also only classified fetal movements. Concomitant cyclic changes of the variables might not be detected if during episodes of relative "quiescence" some movements are still present.

The data of the present study regarding the human fetus are in agreement with the more recent findings in preterm infants. Using different approaches it was shown that at 30 to $32 \mathrm{wk}$ of gestation heart rate variation and eye and gross body movements are not independent variables and that coordination among the cyclic patterns of these variables is present well before $36 \mathrm{wk}$. At this age this coordination is, however, far from perfect. Although for the whole group a significant correlation was found between 4-min epoch incidence of eye movements and gross body move- ments, this could only be demonstrated for seven of the 11 fetuses. Moreover, changes in the state variables seldom occur exactly at the same time. These data suggest a more or less gradual development of behavioral states. They do not contradict earlier findings in fetuses and newborn infants that fully coordinated behavioral states develop at later ages.

The number of more or less coordinated state changes was identical when fetal heart rate changed from pattern A to B or from $B$ to A. Therefore with the development of states it is likely that the coordination at the different transitions occurs at about the same time. In the near term fetus the duration of a complete cycle of low and high heart rate variation is about $80 \mathrm{~min}(15)$. This is about the same length as that of a REM-non-REM cycle in the newborn infant. The present findings as well as those of others $(5,16)$ indicate a shorter cycle length at earlier gestation.

Acknowledgments. The authors thank Dr. T. Boogert for critical reading of the manuscript.

\section{REFERENCES}

1. Prechtl HFR, Fargel JW, Weinmann HM, Bakker HH 1979 Postures, motility and respiration of low-risk preterm infants. Dev Med Child Neurol 21:3-27

2. Dreyfus-Brisac C 1966 Ontogénèse du sommeil chez le prématuré humain: etude polygraphique. In: Minkowski A (ed) Regional Development of the Brain in Early Life. Blackwell, Oxford, pp 437-457

3. Parmelee AH, Wenner WH, Akiyama Y, Schultz M, Stern E 1967 Sleep states in premature infants. Dev Med Child Neurol 9:70-77

4. Nijhuis JG, Prechtl HFR, Martin CB, Bots RSGM 1982 Are there bchavioural states in the human fetus. Early Hum Dev 6:177-195

5. Hoppenbrouwers T, Combs D, Ugartechea JC. Hodgman J, Sterman MB, Harper RM 1981 Fetal heart rate during maternal wakefulness and slecp. Obstet Gynecol 57:301-309

6. Visser GHA. Dawes GS, Redman CWG 1981 Numerical analysis of the normal human antenatal fetal heart rate. Br J Obstet Gynaecol 88:792-802

7. Awoust J, Levi S 1984 New aspects of fetal dynamics with a special emphasis on eye movements. Ultrasound Med Biol 10:107-116

8. Karch D, Rothe R, Jurich R, Heldt-Hildebrandt R, Lübbesmeier A, Lemburg P 1982 Behavioural changes and bioelectric brain maturation of preterm and full term newborn infants: a polygraphic study. Med Child Neurol 24:30-47

9. Curzi-Dascalova L, Lebrun F, Korn G 1983 Respiratory frequency according to sleep states and age in normal premature infants. Pediatr Res 17:152-158

10. Curzi-Dascalova L, Peirano P, Vicentc G, 1985. Body motility according to sleep states in normal newborn infants: a preliminary study. In: Jones CI, Nathanielsz PW (eds). The Physiological Development of the Fetus and Newborn. Academic Press, London, pp 817-820

11. Dreyfus-Brisac C 1970 Ontogenesis of sleep in human prematures after 32 weeks of conceptional age. Dev Psychobiol 3:91-121

12. Bots RSGM, Nijhuis JG, Martin CB, Prechtl HFR 1981 Human fetal cye movements: detection in utero by ultrasonography. Early Hum Dev 5:8794

13. Dreyfus-Brisac C 1968 Sleep ontogenesis in early human prematurity from 24 to 27 weeks of conceptional age. Dev Psychobiol 1:162-169

14. Dittrichova J, Paul K 1983 Development of behavioural states in very premature infants. Act. Nerv. Sup. (Praha) 25:187-188

15. Visser GHA, Goodman JDS, Levine DH, Dawes GS 1982 Diurnal and other cyclic variations in human fetal heart rate near term. Am J Obstet Gyneco 142:535-544

16. Dierker LJ, Pillay S, Soronkin Y, Rosen MG 1982 The change in fetal activity periods in diabetic and nondiabetic pregnancics. Am J Obstet Gynecol 143:181-185 